\title{
Rabaska
}

Revue d'ethnologie de l'Amérique française

\section{Cimetières - Patrimoine pour les vivants}

Volume 7, 2009

URI : https://id.erudit.org/iderudit/038339ar

DOI : https://doi.org/10.7202/038339ar

Aller au sommaire du numéro

Éditeur(s)

Société québécoise d'ethnologie

ISSN

1703-7433 (imprimé)

1916-7350 (numérique)

Découvrir la revue

Citer ce document

(2009). Cimetières - Patrimoine pour les vivants. Rabaska, 7, 103-103.

https://doi.org/10.7202/038339ar

Ce document est protégé par la loi sur le droit d'auteur. L'utilisation des services d'Érudit (y compris la reproduction) est assujettie à sa politique d'utilisation que vous pouvez consulter en ligne.

https://apropos.erudit.org/fr/usagers/politique-dutilisation/
Cet article est diffusé et préservé par Érudit.

Érudit est un consortium interuniversitaire sans but lucratif composé de l'Université de Montréal, l'Université Laval et l'Université du Québec à Montréal. Il a pour mission la promotion et la valorisation de la recherche. https://www.erudit.org/fr/ 


\section{Place publique}

Points de vue / livre

\section{Cimetières - Patrimoine pour les vivants}

Comme c'est l'habitude, Rabaska fait appel pour cette rubrique à des experts réputés qui connaissent bien le domaine de l'ouvrage retenu. Pour présenter ce livre monumental, nous avons sollicité trois chercheurs, de milieux différents, dont les points de vue particuliers devraient enrichir les perspectives et alimenter la réflexion de nos lecteurs. Madeleine Lassère est docteur en Histoire, maître de conférences de l'Université Michel-de-Montaigne à Bordeaux et auteur de Villes et cimetières en France de l'Ancien Régime à nos jours (Paris, L'Harmattan, 1997). Historienne et traductrice, Sally Ross travaille dans le champ des études acadiennes depuis plus de trente ans; en 2003, elle entreprenait une recherche sur les cimetières des Acadiens rétablis en Nouvelle-Écosse après 1764, projet auquel elle travaille toujours. Les travaux de Philippe Dubé, qui est professeur de muséologie à l'Université Laval et directeur du Laboratoire de muséologie et d'ingénierie de la culture (LAMIC), portent actuellement sur les pratiques de muséologie populaire et la mise en exposition, ce qui a été le cas de cet ouvrage.

Jean Simard et François Brault Cimetières - Patrimoine pour les vivants Québec, Les Éditions GID, 2008, 451 p. ISBN 9782922668414

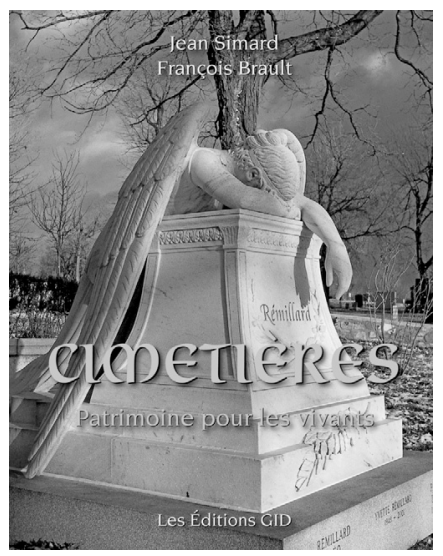

